Purdue University Purdue e-Pubs

$1-1-1997$

\title{
Rational Speculators and Exchange Rate Volatility
}

\author{
J.A. Carlson \\ Purdue University \\ C. L. Olser \\ Purdue University
}

Follow this and additional works at: http:// docs.lib.purdue.edu/ciberwp

Carlson, J. A. and Olser, C. L., "Rational Speculators and Exchange Rate Volatility" (1997). Purdue CIBER Working Papers. Paper 124. http://docs.lib.purdue.edu/ciberwp/124 


\title{
Rational Speculators and Exchange Rate Volatility
}

\author{
John A. Carlson \\ Purdue University \\ C. L. Osler \\ Federal Reserve Bank of New York
}

\section{7-005}

Center for International Business Education and Research Purdue University Krannert Graduate School of Management 1310 Krannert Building

West Lafayette, IN 47907-1310

Phone: (765) 494-4463

FAX: (765) 494-9658 


\title{
RATIONAL SPECULATORS AND EXCHANGE RATE VOLATILITY
}

\begin{abstract}
This paper suggests a structural connection between rational speculative activity and exchange rate volatility. We note that, when Friedman originally claimed that rational speculators must smooth exchange rate, he excluded interest rate differentials from his interpretation of speculator behavior. If interest rates matter, rational speculators could sometimes violate Friedman's description, and buy a currency whose value is relatively high or sell a currency whose value is low. In consequence, the presence of rational, fully informed speculators might increase the volatility of a floating exchange rate. Speculation is stabilizing at low levels of speculative activity and destabilizing at high levels. (J.E.L. codes F31, G12. Key Words: Exchange Rate, Exchange Rate Volatility, Rational Speculation, Noise Traders)

John A. Carlson

Krannert School of Management

Purdue University

C. L. Osler

Federal Reserve Bank of New York
\end{abstract}

First Draft: May 1994

Revised: March 1997

The views expressed in this paper are those of the authors and do not necessarily reflect those of the Federal Reserve Bank of New York or the Federal Reserve System. Please address correspondence to: Carol Osler, Federal Reserve Bank of New York, 33 Liberty Street, New York, NY 10045. Telephone: (212) 720-1717. Fax: (212) 720-6831. E-Mail: Carol.Osler@ny.frb.com. 


\section{Rational Speculators and Exchange Rate Volatility}

\section{Introduction}

A strong correlation seems to exist between trading volume and price volatility in major currency markets (Baillie and Bollerslev 1991, Dacorogna, et al. 1993, Ito et al. 1996). Evidence for such a correlation is also abundant for major equity and bond markets (Cornell 1981, Gallant, Rossi and Tauchen 1992). Some observers claim that speculative activity induces both the high volume and the volatility, while others claim that this cannot be so. The classic statement of the latter position comes from Milton Friedman (1953, p.175): "People who have argued that speculation can be destabilizing seldom realize that this is largely equivalent to saying that speculators lose money, since speculation can be destabilizing in general only if speculators sell when the currency is low in price and buy when it is high." He also points out that speculators who regularly lose money this way will be driven out of the market by speculators with more successful strategies. In sum, Friedman's position is that only rational speculators will survive in the market, and that rational speculation cannot be destabilizing.

Important policy issues hinge on the resolution of this debate. The elimination of capital controls in Europe has coincided with a renewal of intra-ERM turbulence which threatens the viability of the EMU. Viewing this as the result of heightened speculative activity, some observers have argued for the reimposition of capital controls, if only on an as-needed basis (Eichengreen, Rose and Wyplosz 1995). Others with a similar view of speculative activity have argued for the imposition of a foreign-exchange turnover tax (Tobin 
1974; Eichengreen, Tobin and Wyplosz 1994). If Friedman is right, however, a policyinduced reduction of speculative flows would increase foreign exchange volatility, worsening rather than improving the situation.

This paper shows that rational speculators can but need not increase exchange rate volatility and that, contrary to Friedman's (1953) argument, the circumstances under which they might increase volatility are plausible. An examination of Friedman's line of reasoning reveals that it does not incorporate interest rates or risk, both crucial factors for many speculators when they choose the size and direction of their positions. For example, changing interest differentials across countries can lead rational speculators to buy currency even when its price is "high," driving the exchange rate even higher, or sell when it is "low," driving the exchange rate even lower, in this way "destabilizing" the exchange rate.

The result is derived in a straightforward model of the foreign exchange market with two types of traders: "speculators" and "current account traders." Our speculators are rational and fully informed. Current account traders are analogous to liquidity traders in standard finance models, who can be interpreted realistically in the foreign exchange context as importers and exporters of goods and services.

We find that speculators' effect on exchange rate volatility varies according to the types of shocks hitting the market, and we divide these shocks into two categories. Some shocks, such as changes in liquidity demand, do not affect speculators' preferred portfolio positions directly. An increase in speculation will dampen the exchange-rate impact of these shocks, consistent with Friedman's view. Other shocks, such as changes of interest rates or risks, do directly change speculators' preferred portfolio positions. As more speculators are 
introduced into the market, their total reaction to these shocks increases, inducing a rise in the exchange rate's reaction to the shock -- an outcome entirely at variance with Friedman's view. These mixed effects of speculators on exchange rate volatility sort themselves out according to the level of speculative activity. At low levels of speculative activity, the Friedman effect dominates and the introduction of more speculators reduces exchange rate volatility; at high levels the reverse is true.

The results of the paper support Flood and Taylor's (1995) observation that there may be "speculative forces at work in the foreign exchange market that are not reflected in the usual menu of macroeconomic fundamentals" (p. 9). In particular, the results suggest that the fundamental determinants of exchange rate dynamics include microstructural factors such as the extent of speculative activity.

By pointing to the potential importance of microstructural factors in exchange rate dynamics, our results could potentially help explain the increase in real and nominal exchange rate volatility following the industrial world's 1973 shift to floating exchange rates. Evidence provided in Flood and Rose (1992) and Baxter and Stockman (1989) strongly suggests that this change cannot be explained by increased volatility among underlying macroeconomic variables. The results of the present paper suggest that the enormous increase in speculative activity since 1973 could provide an alternative explanation.

Our analysis also suggests a possible explanation of the strong high-frequency connections between the activity of speculators and financial price volatility (such as that highlighted by Ito et al. 1996). French and Roll (1986) divide the possible explanations for these observed connections into three groups, one which relies on public information, one 
which relies on private information, and a third which relies on pricing errors. Our analysis suggests a fourth explanation, orthogonal to these original three: a rise in speculative activity could fundamentally affect financial price dynamics, even controlling for information availability and assuming rational pricing, by changing the way prices respond to information.

The conclusion that speculators can increase financial price volatility is certainly not new. Numerous examples of destabilizing speculation were developed in response to Friedman's claim. Early suggestions came from Baumol (1957), Stein (1961), and Farrell (1966). More recently, Hart and Kreps (1986) show that "speculative activity in an economy in which all agents are rational, have identical priors, and have access to identical information may destabilize prices, under any reasonable definition of stabilization" (p. 927). Likewise, Stein (1987) shows that "introducing a new group of speculators into the spot market for a commodity can destabilize prices" (p. 1124), even when speculators are fully informed and have rational expectations. Hau (1995) shows that speculators could increase exchange rate volatility if individual exchange rate expectations differ.

Though the mechanisms highlighted in these earlier papers are all plausible, many rely on a set of narrowly defined circumstances that may not be present in reality. For example, the Hart and Kreps (1986) model requires a very specific relationship between stochastic consumption behavior and signals about that behavior. Stein's (1987) model requires that the new group of speculators introduced to the market have access to an information source unavailable to the original speculators. The mechanism highlighted here, by contrast, will always operate in foreign exchange markets, so long as speculators concern 
themselves with interest rates as well as expected exchange-rate changes. Analogous mechanisms can also be found in other financial markets. In stock and commodity markets, for example, changes in the domestic interest rates will directly affect speculators and could cause them to destabilize rather than stabilize prices.

Non-rational speculators could also destabilize financial prices, as shown in a group of papers including Frankel and Froot (1990) and De Long, Schleifer, Summers and Waldmann (1990). Though the present paper is concerned with rational speculators, its results are not inconsistent with these important papers.

This paper does not address the welfare implications of speculative behavior. Though there is a presumption among naive observers that increased volatility reduces welfare, academics have noted repeatedly that the reverse could be true (see, for example, Stein [1987]). Since the welfare of non-speculative agents is not modeled explicitly here, the paper focuses exclusively on the implications of speculative activity for exchange rate dynamics, without considering whether changes in those dynamics benefit or harm welfare.

In Section II, we develop and solve the model. Section III analyzes the dynamics associated with specific types of shocks and Section IV shows how the degree of speculation affects the overall exchange-rate volatility. A few extensions are considered in Section V and Section VI concludes.

\section{The Model}

Our model involves two types of agents, liquidity traders and rational speculators, and is driven by two types of exogenous shocks, those that affect goods and services trade and 
those that affect interest differentials. Similar models are used in Osler (1995), which considers the impact of speculators' horizons on exchange rate dynamics, and Osler (1997), which considers the impact of short-term speculators on the propagation of exchange rate shocks. The model used here differs critically from these previous models, however, since it includes interest differentials. We first describe the two types of agents, and then describe the balance of payments equilibrium condition through which they interact. We finish this section by summarizing the solution to the model (the solution algorithm is presented in the appendix).

\section{A. Types of Traders.}

Current Account Traders. In the asset-pricing literature it is by now common for models to include "liquidity" traders, who buy and sell the asset in question for purposes unconnected with speculation. These agents are sometimes modeled as having demands which are linear in the level of the asset price in question plus a random disturbance term (see, for example, Dow and Gorton, 1993). In the foreign-exchange market these agents are immediately recognizable as importers and exporters, who maximize profits from trading goods and services. Though they could engage in speculation, these agents generally choose not to do so, reasoning that their expertise in this area is limited. In effect, they take potential losses from failing to speculate as an opportunity cost of pursuing their chosen line of business. We will discuss these agents as if they entirely abstain from speculating, which is not a bad approximation to their actual behavior, in aggregate. However, this interpretation is not critical: the model can be interpreted in a way which includes speculation by these agents, as will be discussed below. 
In representing these agents in our model we leave their profit-maximizing decision in the background, and focus on an abstract interpretation of their associated currency demand. Their demands for currency are, therefore, determined predominantly by the level of the exchange rate and by factors unconnected to the exchange rate which appear random, from the perspective of the rest of the market. Let $e_{t}$ denote the log of the domestic price of foreign currency. Domestic importers and/or foreign exporters will buy foreign currency with domestic currency. When the foreign currency appreciates, or $e_{t}$ rises, some or all of the appreciation will be passed through to higher import prices (measured in domestic currency), leading to declines in both import volume and foreign currency demand. Foreign importers and/or domestic exporters will supply foreign exchange and their supply in response to exchange rate changes will depend on the extent of the pass through and on the price elasticity of exports.

The net current-account/liquidity demand for foreign currency is defined as the difference between importers' demand and exporters' supply, or

$$
C A_{t}=C+S \varepsilon_{t}-S e_{t} .
$$

where $C$ and $S$ are constant and $\varepsilon_{t}$ is a random shock. $S$ is assumed to be positive, so that an appreciation of the foreign currency (higher $e_{\ell}$ ) lowers the net liquidity demand for foreign currency. The random shock is intended to summarize all factors other than the exchange rate that alter net foreign currency demand from current account traders, such as barriers to trade, price levels, and military engagements. These influences could very well be intertemporally correlated and need not be stationary. One can think of $C A_{t}$ as the current account of the foreign country.' 
If the exchange rate, in the absence of any speculation, had to adjust to keep the current account equal to zero, then from equation (1),

$$
e_{t}=\bar{e}+\varepsilon_{t}
$$

where $\bar{e} \equiv C / S$ is the exchange rate that makes $C A_{t}=0$ in the absence of shocks. On the assumption that the expected value of $e_{t}$ is zero, we will call $\bar{e}$ the long-run equilibrium exchange rate. $^{2}$

Rational speculators. Speculators represent a broad class of agents who exploit exchange-rate changes to make profits. This group includes interbank traders, foreignexchange mutual-fund managers, and individual currency speculators. The group also includes managers of international bond funds and other portfolio managers who invest internationally. The primary characteristics of these agents are (i) they invest internationally in interest-bearing securities or loans and thereby incur exchange risk and (ii) they are paid according to the profits they make by investing funds which, in most cases, they do not own.

To reflect these attributes of the model's speculators it is natural to adopt what has become a convention among modelers in the theoretical asset-pricing literature: speculators have a constant absolute risk aversion utility function,

$$
U_{t+1}=-\exp \left[-\theta \pi_{t+1}\right]
$$

where $\pi_{t+1}$ represents an individual speculator's profits. To earn these profits the speculator takes a bet each period by establishing a position of size $b_{t}$, which is measured in units of foreign currency. The optimal bet, to be derived shortly, depends on expected profits. Actual profits are defined as follows: for every unit of currency bet, the speculator earns the 
change in the log of the exchange rate, $e_{t+1}-e_{p}$ plus the short-term interest differential across countries:

$$
\pi_{t+1}=b_{t}\left[e_{t+1}-e_{t}+\delta_{t}\right]
$$

where $\delta_{t} \equiv i_{t}^{*}-i$ denotes the excess of the foreign interest rate $i_{t}^{*}$ over the domestic interest rate $i_{r}$. (Note that our central conclusions are not driven by the fact that interest rates affect speculators but not current account traders. See Carlson and Osler, 1996.) It will be assumed that speculators are not limited in the size of their position, be they short or long.

Under the assumption, to be examined later, that profits are distributed conditionally normally, speculators who maximize expected utility will behave as if they are maximizing the welfare function

$$
W_{t}=E_{t}\left(\pi_{t+1}\right)-(\theta / 2) \operatorname{Var}\left(\pi_{t+1}\right)
$$

where $E_{t}\left(\pi_{t+1}\right)$ denotes the expected level, $\operatorname{Var}\left(\pi_{t+1}\right)$ denotes the variance of a speculator's next-period profits conditional on information available at time $t$, and $\theta$ denotes a speculator's level of absolute risk aversion. The optimal bet will be proportional to expected profits and inversely proportional to risk aversion and risk itself:

$$
b_{t}=q_{t}\left[E_{t}\left(e_{t+1}\right)-e_{t}+\delta_{t}\right]
$$

where

$$
q_{t}=\frac{1}{\theta \operatorname{Var}\left(e_{t+1}\right)}
$$


10

$\operatorname{Var}\left(e_{t+1}\right)$ is the expected variance of the exchange rate conditional on information at time $t$. Later, when we solve explicitly for the exchange rate and for its variability, the conditional variance will be seen to depend on parameters generating the shocks. Since we are dealing with a standard utility function it is not surprising that the linear form of this bet function is also standard in the theoretical asset-pricing literature.

If there are $N$ such speculators, their desired portfolio holdings can be written:

$$
N b_{t} \equiv B_{t}
$$

Changes in $B_{t}$ can be viewed as the foreign country's capital account. A positive change $\left(B_{i}\right.$ $B_{t-1}>0$ ) is a capital flow from the domestic to the foreign country. ${ }^{3}$ Note that $N$ need not be interpreted literally as the number of speculators. Instead, we can view $N$ as a measure of total hours spent on speculative activity per period, where some of those hours could be associated with speculative activity of current account traders.

It is convenient to re-express the capital account as follows:

$$
B_{t}=N q_{i}\left(E_{t} e_{t+1}-e_{t}+\delta_{t}\right)=Q_{t}\left(E_{t} e_{t+1}-e_{t}+\delta_{t}\right)
$$

The parameter $Q_{t} \equiv N q_{t}$ represents a measure of total speculative trading in the foreign exchange market.

\section{B. Market Solution.}

Assume floating exchange rates and no intervention by central banks in the foreign exchange market. Consequently, the exchange rate adjusts to maintain the following balance of payments equation:

$$
C A_{t}+B_{t}-B_{t-1}=0
$$


A well-known but important point to note is that there must be a current-account surplus or deficit in order for speculators to make any change in their net holdings of foreign assets.

Note that this equilibrium condition requires flow equilibrium in the foreign exchange market. Models which relied on this equilibrium condition, the Mundell-Fleming model in particular, fell out of favor with the advent of asset market models in the 1970s, but the primary shortcoming of the earlier models was an absence of maximizing behavior on the part of speculative agents. This problem is not shared by the present model, however, since, as indicated by equations (6) and (7), our utility-maximizing speculators must be satisfied with their stock position in foreign exchange each period. A renewed appreciation of the importance of flow equilibrium in currency markets was forcefully advocated as early as Kouri (1981), and more recently by Lyons [1995] and Goodhart [1988]. This condition has been included in some relatively recent works (Bhattacharya and Weller [1993], Lyons [1995]). The importance of flow is further underlined by its centrality to the profit-making strategies of interbank traders. ${ }^{4}$

Substituting from (1) and (9) into this balance of payments equation and collecting terms, we have

$$
E_{t} e_{t+1}-\left(1+S / Q_{t}\right) e_{t}-\frac{Q_{t-1}}{Q_{t}}\left[E_{t-1} e_{t}-e_{t-1}\right]=-\left[C+S \epsilon_{t}+Q_{t} \delta_{t}-Q_{t-1} \delta_{t-1}\right] / Q_{t}
$$

For convenience we define the change in the interest rate differential as follows: $\Delta_{t}$ $\equiv \delta_{t}-\delta_{t-1}$. We will take $\Delta_{t}$ as the second source of exogenous shocks to this foreign exchange market. $^{5}$ 
Assuming that $N, S, \theta$, and the variances and covariances of the exogenous shocks are constant, we can find a solution in which $\operatorname{Var}\left(e_{t+1}\right)$ is constant. In that case, $Q_{t}$ must also be a constant. Our procedure, with technical details shown in the appendix, will be to assume a constant $Q$ and solve equation (11) for $e_{t}$ as a function of $e_{t-1}$, current shocks, and projections of future shocks. We ignore bubble solutions. With the solution for (11) we can readily determine the unique constant conditional variance of the exchange rate and study how different values of parameters affect that variance.

To maintain our focus on the issue of whether speculation is stabilizing, we initially consider the special case in which the shocks are independent of each other and of all past shocks, and all future shocks have zero expected values. ${ }^{6}$ More general possibilities are examined in Section V.

With these base assumptions, the exchange rate's dynamics can be written:

$$
e_{t+1}=\lambda e_{t}+(1-\lambda) \bar{e}+(1-\lambda) \varepsilon_{t+1}+\frac{\lambda}{1-\lambda} \Delta_{t+1}
$$

where

$$
\lambda=\varphi-\sqrt{\varphi^{2}-1}, \varphi \equiv 1+\frac{S}{2 Q}
$$

is the smaller root of the characteristic equation:

$$
l^{2}-(2+S / Q) \lambda+1=0 \text {. }
$$

As shown in the appendix, there is a unique solution for $Q, \lambda$, and $\operatorname{Var}\left(e_{t}\right)$ as functions of $N, S, \theta, \operatorname{Var}(\varepsilon)$, and $\operatorname{Var}(\Delta)$. Since our equilibrium exchange rate generating process is linear in the shocks, it is sufficient to assume that the shocks are normally distributed -- as 
we do henceforth -- to conclude that the exchange rate itself will be normally distributed, as required earlier. Had we chosen to examine a nonlinear equilibrium, this property of normalcy might not have held.

Note that $\lambda$, a positive fraction, is close to zero when $Q$ is close to zero and approaches one as $Q$ is very large. Since $\lambda$ and $Q$ are monotonically related, and since $Q$ is a measure of speculative activity as discussed earlier, we will follow the dictates of analytical convenience and treat $\lambda$ as our measure of speculative activity for the remainder of the paper.

\section{Speculation and Market Dynamics}

Before presenting an expression for the variability of the exchange rate, which we do in Section IV, it is worth pausing to gain a better understanding of exchange rate dynamics by considering the market response to each type of shock. We first consider how fullyinformed rational speculators perform their function of offsetting an unanticipated transitory current-account shock. We then show how the market reacts to an unanticipated change in the interest-rate differential.

\section{A. Transitory Trade Shocks}

Suppose at time $t$ there is a transitory trade shock of $S \varepsilon_{t}$ and no interest-differential shock. For intuitive convenience, assume we enter the period with the exchange rate at its long-run equilibrium, speculators' outstanding positions at zero, and the interest differential at zero. In this case equation (12) becomes:

$$
e_{t}=\bar{e}+(1-\lambda) \varepsilon_{r} .
$$


By way of comparison, note that the exchange rate would be $e_{t}=\bar{e}+\varepsilon_{t}$ in the absence of speculators. Thus the initial impact of a trade shock $(\varepsilon)$ is smaller when speculators are present than when they are absent. In this sense, speculators can be said to stabilize the exchange rate in response to current-account shocks, just as described by Friedman (1953).

To understand why rational speculators temper the exchange rate's response to a transitory trade shock, imagine the first speculator to observe this market. ${ }^{7}$ If the speculator refrained from entering the market, s/he would rationally expect the exchange rate to fall from $\bar{e}+\varepsilon$, back to $\bar{e}$ in the next period. This implies a profit-making opportunity, to take advantage of which the speculator would sell foreign currency. Those very sales would put downward pressure on the exchange rate, as a result of which the exchange rate would initially rise by less than $\varepsilon$-- say by $(1-x) \varepsilon$, where $x<1$.

The speculator's presence will affect not only the initial exchange rate, but also those of subsequent periods. For example, in the next period the speculator will need to repurchase the foreign exchange in order to realize profits, putting sufficient upward pressure on the exchange rate to raise it above its unconditional mean. Once again, if the speculator took no position between the second and third periods, the speculator would rationally anticipate that the exchange rate would decline to its unconditional mean. The natural choice is again to take a short position in anticipation of such a decline (though in this second round s/he will sell a smaller amount, since the anticipated exchange-rate decline is smaller). Through this 
process the speculator affects all future exchange rates, though to a progressively smaller degree.

In a full rational expectations equilibrium, with multiple speculators, the speculators will take account of their aggregate effect on exchange rate dynamics. (It is this equilibrium that we describe with equation (12) or, in more general cases, with equation (A.8) in the appendix.) In response to a trade shock of $S \varepsilon$ the exchange rate will initially rise by $(1-\lambda) \varepsilon$. $\lambda$ summarizes the amount of smoothing pressure exerted by speculative activity, which is determined by the total amount of speculator sales in response to the shock. This selling pressure depends, in turn, on the number of speculators, their risk aversion, and the exchange rate's (endogenous) volatility.

Our risk-averse speculators will hold a short position in foreign currency only if they expect to be rewarded for that risk. Their risk premium can be defined as the expected excess returns on a foreign currency posistion. From equations (6) and (7),

$$
E_{t} e_{t+1}-e_{t}+\delta_{t} \equiv \text { Risk Premium } \text { Pro }_{t} \theta \operatorname{Var}(e)
$$

The risk premium is proportional to three factors: (1) the outstanding stock of foreign currency held per speculator at time $t, b_{i}$; (2) speculators' risk aversion, $\theta$; (3) the exchange rate's conditional variability. The presence of all of these factors is consistent with many standard models.

If speculators are risk neutral $(\theta=0)$, they will take whatever positions are necessary to drive the risk premium close to zero. If speculators are risk averse, then the risk premium will be time-varying. What causes these variations, however, is not necessarily changes in 
the inherent riskiness of one currency relative to another, or changes in risk aversion, our standard suspects. In addition to these factors, variations in risk premia are driven by changes in the profit opportunities facing speculators: these agents take positions whenever shocks to the foreign exchange market create opportunities for speculative profits, with the size of those positions and equilibrium risk premiums jointly determined period-by-period.

\section{B. Interest-Rate Differential Shocks.}

Now consider how the market reacts to a change in interest rates. Assume once again that, up through period $t-1$, the exchange rate was at its long-run equilibrium and the interest differential was zero. Assuming as well that there are no trade shocks, equation (12) becomes:

$$
e_{t}=\bar{e}+\frac{\lambda}{1-\lambda} \Delta_{t}
$$

A rise in the amount of speculative activity (higher $Q$ and higher $\lambda$ ), will increase the exchange rate's response to the shock. Thus for interest-rate shocks, additional speculators do not play a stabilizing role. This contrasts sharply with the way speculators subdue the exchange rate's response to trade shocks, discussed earlier.

Where does this destabilizing influence come from? A simple, model-free explanation points to the fact that speculators may deviate from conventional wisdom and buy when the exchange rate is "high" or sell when it is "low"(in each case relative to its unconditional mean), when interest rate differentials suggest that there are profits to be made. 
For a more model-specific explanation, it is helpful to begin with an understanding of the system's overall response to an interest shock. Suppose that interest differentials and speculators' positions begin at zero, and there is a positive shock $\Delta_{t}>0$, so that $\oint=4$., while trade shocks remain zero. Other things equal, the rise in foreign relative to domestic interest rates will cause speculators to increase their holdings of foreign assets. In trying to purchase additional currency they will bid up the price, inducing a corresponding supply from current-account traders.

After the exchange rate's initial rise to the shock, speculators must expect a future fall in the value of foreign currency $\left(e_{t}\right)$ since the long-run exchange rate in our example does not change. By taking the expected value of equation (12) at time $t$ and re-arranging terms we can show that the expected exchange rate decline next period is proportional to the gap between the current exchange rate and its long run value:

$$
E_{t} e_{t+1}-e_{t}=-(1-\lambda)\left(e_{t}-\bar{e}\right)
$$

This decline is, of course, determined by speculators' continued equilibrium adjustments to the shock. According to equation (6), their new long-term desired foreign currency holdings will be $q \delta_{r}$. Initially, however, they acquire only a part of that position because the expected return on foreign assets is less than the foreign interest rate (by the amount of expected depreciation) ${ }^{8}$ Speculators slowly raise their foreign assets towards that long-run desired level. Those same additional purchases are the force that sustains the foreign currency's short-run value above its long-run equilibrium value. The currency declines monotonically because speculators purchase a slightly smaller amount each period. 
Once speculators have taken a new foreign currency position in any period, they must expect to be rewarded for carrying that position. The risk premium in our specific example with $\delta_{t}=\Delta_{t}$ will be proportional to the interest differential itself: ${ }^{9}$

$$
\begin{aligned}
E_{t} e_{t+1}-e_{t}+\delta_{t}= & \delta_{t}-\lambda \Delta_{t}, \\
& =(1-\lambda) \Delta_{t}
\end{aligned}
$$

Having described the model's response to an interest differential shock we can now examine how the system responds to an increase in speculative activity. Suppose there is a rise in $N$, the number of speculators, or a decline in the risk aversion of a given population of speculators. In each case, other things equal, there will be a greater speculative response to a given interest shock. There will be more speculators trying to achieve a position of $q \delta_{r}$, or, alternatively, the total desired increase in foreign currency holdings for a given population of speculators will be higher because the new desired long-run position of each speculator will be greater.

This captures intuitively the reason why a rise in speculative activity increases the exchange rate's response to an interest shock. Of course, the system's overall response is substantially more complex than suggested so far. Most importantly, the exchange rate's variance adjusts endogenously, as discussed in Section IV, below, and this in turn causes speculators to adjust their bet coefficients. Once these endogenous adjustments work themselves out, however, an exogenous rise in speculative activity ultimately leads to higher $Q$, higher $\lambda$, and a stronger initial exchange rate response to an interest differential shock. 


\section{Speculation and Exchange Rate Volatility}

We are now ready to examine how the amount of speculative activity influences the conditional variance of the exchange rate. We first compute the conditional variance of the exchange rate based on equation (12). At time $t+1$ the only new information comes from $\varepsilon_{t+1}$ and $\Delta_{t+1}$, so the unexpected exchange rate change will be

$$
e_{t+1}-E_{t} e_{t+1}=(1-\lambda) \varepsilon_{t+1}+\frac{\lambda}{1-\lambda} \Delta_{t+1}
$$

This allows us to calculate the conditional variance directly:

$$
\operatorname{Var}\left(e_{t+1}\right)=E_{t}\left[e_{t+1}-E_{t} e_{t+1}\right]=(1-\lambda)^{2} \operatorname{Var}(\varepsilon)+\frac{\lambda^{2}}{(1-\lambda)^{2}} \operatorname{Var}(\Delta),
$$

assuming $\varepsilon$ and $\Delta$ are uncorrelated.

From this expression, and the monotonic relationship between $\lambda$ and $N$ mentioned earlier, we can infer a number of important aspects of the relationship between speculative activity and exchange rate volatility:

1. If only current-account shocks occur, with $\operatorname{Var}\left(\Delta_{t+1}\right)=0$, then the conditional variance of the exchange rate declines monotonically with the amount of speculation. In the limit, as $\lambda$ approaches one, the conditional variance goes to zero.

2. If only interest-rate shocks occur, with $\operatorname{Var}\left(\varepsilon_{t+1}\right)=0$, then the conditional variance of the exchange rate increases monotonically with the amount of speculation. As 
speculative activity rises, and $\lambda$ approaches one, the conditional variance becomes arbitrarily large.

3. If both types of shocks occur, then, as speculative activity increases and $\lambda$ rises from zero, the conditional variance of the exchange rate first falls, reaches a minimum, and then rises without limit.

4. Denote by $\lambda *$ the $\lambda$ at which the conditional variance is at a minimum. From equations (6) and (7) we can also see that an individual speculator's optimal position varies inversely with $\operatorname{Var}\left(e_{t+1}\right)$. This means at low levels $\lambda$ - and thus with little speculation -- an individual speculator's position and expected profits rise as additional speculators enter the market. These reach a maximum when speculative activity is such that $\lambda=\lambda^{*}$, and then fall as speculative activity continues to increase.

\section{Extensions}

In our analysis so far we have used just one measure of volatility and assumed that all shocks are independently and identically distributed with zero means. In this section, we introduce other measures of volatility that have appeared in the literature and consider how different patterns of shocks might alter the impact of added speculation. The results indicate that variations in measures of volatility or in patterns of shocks do not change our conclusion that speculation can be destabilizing. 


\section{A. Other Measures of Volatility}

DeLong et al. (1990) use the distance of the exchange rate from its "fundamental" in their three-period model as their measure of whether and how much speculators destabilize prices. In an infinite-period model such as the one presented here this is analogous to using the unconditional variance of the price level: $E\left[e_{t+1}-\bar{e}\right]^{2}$. The conditional variance we used in the prior section represents the unexpected movements in the exchange rate that makes speculation risky. The unconditional variance is a measure of the overall wanderings of the exchange rate and is the sort of statistic that many economists examine when trying to characterize market behavior.

In the two-period model of Stein (1987), price stability is measured in terms of the effect of speculators on period-2 price changes. In focusing on price changes, we can look at either the conditional or unconditional variance of the change. The conditional variance of the change in the exchange rate, $E_{t}\left[e_{t+1}-e_{t}\right]^{2}$, differs from the conditional variance of the exchange rate, $\operatorname{Var}\left(e_{t+1}\right)=E_{t}\left[e_{t+1}-E_{t} e_{t+1}\right]^{2}$, whenever the exchange rate next period is expected to differ from its current level.

The unconditional variance of the change in the exchange rate $E\left[e_{t+1}-e_{t}\right]^{2}$ is a statistic that is of interest to economists when there are trends in the exchange rate and the unconditional variance of the exchange rate's level is undefined. It is often computed empirically when the "fundamental" is changing in unknown ways.

For each of these equally reasonable definitions of exchange-rate volatility, there are at least two approaches to considering whether speculation is destabilizing. Stein (1987) essentially looks at the "marginal" effects of speculation, asking whether the introduction of 
one new speculator (or a group of new speculators) changes price volatility if some speculators were already active in the market. Alternatively, one might be interested in the "average" effects of speculation, that is, whether volatility is higher or lower with some speculators than with none.

In the case of independent and identically distributed mean-zero shocks, all of these measures of volatility yield the same falling-then-rising pattern as the level of speculative activity increases. In fact, the minimum variance also occurs at the same value of $\lambda$. For example, the unconditional variance of the exchange rate is shown in the appendix to be:

$$
E\left[e_{t+1}-\bar{e}\right]^{2}=\frac{(1-\lambda)}{(1+\lambda)} \operatorname{Var}(\varepsilon)+\frac{\lambda^{2}}{(1-\lambda)^{2}} \frac{1}{1-\lambda^{2}} \operatorname{Var}(\Delta)
$$

The pattern with regard to increases in speculative activity -- and $\lambda$-- is precisely the same as it is with the conditional variance. The only difference is that the variability attributable to each of the shocks has been magnified by a factor of $1 /\left(1-\lambda^{2}\right)$.

\section{B. Autocorrelated Current-Account Shocks}

Most shocks that affect demand for currency are autocorrelated to some degree. A rise in real income in one country that raises demand for the exports of the other country will certainly last a while. Likewise a rise in one country's price level will tend to have a fairly lasting effect on demand for exports and currency of the other country. To capture this possibility we can modify the structure of the disturbances to the current-account sector of the model to make those disturbances autocorrelated. Specifically, suppose the disturbance, 
originally the mean zero i.i.d. variable $\varepsilon_{\text {, }}$, is instead an $\mathrm{AR}(1)$ variable with a mean zero i.i.d. disturbance, $\omega_{t}$ :

$$
\varepsilon_{t}=\rho \varepsilon_{t \cdot 1}+\omega_{t}
$$

where $0<p<1$. In that case, the exchange rate's conditional variance can be shown to be:

$$
E_{i}\left[e_{t+1}-E_{t} e_{i+1}\right]^{2}=\frac{(1-\lambda)^{2}}{(1-\rho \lambda)^{2}} \operatorname{Var}(\omega)+\frac{\lambda^{2}}{(1-\lambda)^{2}} \operatorname{Var}(\Delta)
$$

When $\rho=0$, this reduces to the conditional variance in the basic model, presented as (22). Higher values of $\rho$ increase the coefficient on $\omega_{t+1}$ and hence increase variability attributable to current account shocks. This is because when a shock occurs, the market reacts not only to the new current value of $\varepsilon_{t+1}$ but also takes into account how the shock affects expected future values.

The pattern of exchange rate volatility falling and then rising as speculation increases is still the same as before. The variability attributable to current-account shocks approaches a lower bound of zero while the variability attributable to interest-rate shocks becomes arbitrarily large. This pattern is true of other measures of volatility as well because, at higher values of $\lambda$, the rising impact of the interest-rate shocks always eventually dominates. (Proof of these claims is available from the authors upon request.) 


\section{Mean-Reverting Interest Rates}

Our original specification assumed that the interest-rate differential has a unit root. While this is consistent with some empirical analyses, it would seem worthwhile nonetheless to check the implications of relaxing this assumption. Specifically, let us assume instead that the interest rate differential follows a stationary $A R(1)$ process with first-order autocorrelation coefficient $\alpha$ and mean-zero i.i.d. disturbance $\eta_{t}$ :

$$
\delta_{i}=\alpha \delta_{t-1}+\eta_{t}
$$

with $0<\alpha<1$. If the current-account shocks are again assumed to be i.i.d. with zero mean, the exchange rate now has the following solution:

$$
e_{t+1}=\lambda e_{t}+(1-\lambda) \bar{e}+(1-\lambda) \varepsilon_{t+1}+\frac{\lambda}{1-\alpha \lambda} \eta_{t+1}-\frac{\lambda(1-\alpha)}{1-\alpha \lambda} \delta_{t}
$$

The exchange-rate dynamics under the random-walk hypothesis for the interestrate differential considered earlier can be seen to hold in (27) when $\alpha=1$. Less persistence is represented by lower values of $\alpha$ and there are now two terms to consider, one associated with $\eta_{t+1}$ and a second associated with $\delta_{t}$. To understand why the coefficient on the latter is negative, keep in mind that, with mean reversion, a high current interest-rate differential means declining differentials over the future. This, in turn, implies that speculators will be planning concurrent decreases in their holdings of foreign exchange. A smaller value of $\alpha$ makes the effect stronger because the mean reversion occurs more rapidly. 
A positive current interest-differential shock $\eta_{t+1}>0$ still raises the exchange rate but the effect is monotonically related to the value of $\alpha$. In the limit, as $\alpha$ goes to zero and the interest-rate differentials are entirely transitory (i.e., $\delta_{t}=\eta_{t}$ ), there is still an initial impact of $\eta_{t+1}$ on the exchange rate but that effect is completely reversed the next period.

We can use (27) to calculate the conditional variance

$$
E_{i}\left[e_{t+1}-E_{t} e_{t+1}\right]^{2}=(1-\lambda)^{2} \operatorname{Var}(\varepsilon)+\frac{\lambda^{2}}{(1-\alpha \lambda)^{2}} \operatorname{Var}(\eta)
$$

The pattern still holds of the variance first falling and then rising as $\lambda$ increases. So, beyond a critical amount of speculation, increased speculative activity will increase exchange rate variability even with mean-reverting interest-rate differentials. (Note that, for $\alpha<1$, it is no longer true that the coefficient on the interest-differential shocks -- and the potential effect of speculators on exchange rate volatility -- becomes arbitrarily large as $\lambda$ approaches 1.)

\section{Conclusions}

This paper has developed a model highlighting a structural connection between rational speculative activity and exchange-rate volatility based on plausible circumstances. The source of speculators' potentially destabilizing influence is their direct response to certain types of shocks, such as interest rate changes. Other shocks to which speculators will respond directly would include changes in taxes and transactions costs, changes in perceived risk, or changes in their own risk aversion. Unlike the 
speculation-volatility connections suggested by French and Roll (1986), the one suggested here does not rely on informational asymmetries between speculators and other agents. Instead, it suggests that the presence of speculators changes the exchange rate's response to given shocks.

The model also shows that rational speculators tend to smooth the effects of certain types of exchange rate shocks-specifically shocks which do not directly affect speculators' desired positions, such as shocks to international trade. When these are the only shocks, speculators who expect (say) a future exchange-rate appreciation will buy foreign exchange immediately, and sell it later, thereby smoothing the price exactly as described by Friedman (1953) in his discussion of speculators' effects on flexible exchange rates. We have shown, however, that there may be times when speculators will buy when the exchange rate is "high"and sell when it is "low" (in each case relative to its unconditional mean), contrary to Friedman's description and yet fully consistent with rationality.

Finally, the model has the property that as the level of speculative activity rises, the variance in the exchange rate falls for small amounts of speculation. However, beyond some point more speculation will increase the variance of the exchange rate and hence destabilize the market. 


\section{References}

Baillie, Richard T., and Tim Bollerslev, 1991, Intra-day and Inter-market Volatility in Foreign Exchange Rates, Review of Economic Studies 58, 565-585.

Baumol, W., 1957, Speculation, Profitability, and Stability, Review of Economics and Statistics $39,263-271$.

Baxter, Marianne, and Alan C. Stockman, 1989, Business Cycles and the Exchange-Rate Regime: Some International Evidence, Journal of Monetary Economics 3, 377-400.

Bhattacharya, Utpal, and Paul Weller, 1993, The Advantage of Hiding One's Hand: Speculation and Central Bank Intervention in the Foreign Exchange Market, University of Iowa Mimeo.

Blanchard, Olivier Jean, and Stanley Fischer, 1989, Lectures on Macroeconomics (MIT Press: Cambridge, MA).

Carlson, John A., and Carol L. Osler, 1996 Rational Speculators and Exchange Rate Volatility, Federal Reserve Bank of New York Staff Reports 13.

Cornell, Bradford, "The Relationship Between Volume and Price Variability in Futures Markets," The Journal of Futures Markets, 1 (Fall 1981), 303-316.

Dacorogna, M.M., U.A. Mueller, R.J. Nagler, R.B. Olsen, and O.V. Pictet, 1993, A Geographical Model for the Daily and Weekly Seasonal Volatility in the Foreign Exchange Market, Journal of International Money and Finance 12, 413-38.

DeLong, J.B., A. Schleifer, L. Summers, and R. Waldmann, 1990, Noise Trader Risk in Financial Markets, Journal of Political Economy 98, 703-738.

Dow, James, and Gary Gorton, 1993, Trading, Communication and the Response of Asset Prices to News, Economic Journal 103, 639-46. 
Eichengreen, Barry, James Tobin, and Charles Wyplosz, 1995, Two Cases for Sand in the Wheels of International Finance, The Economic Journal 105.

Eichengreen, Barry, Andrew Rose, and Charles Wyplosz, 1995, Exchange Market Mayhem: The Antecedents and Aftermath of Speculative Attacks, Economic Policy 21.

Farrell, M., 1966, Profitable Speculation, Economica 33, 183-193.

Flood, Robert P., and Andrew K. Rose, 1993, Fixing Exchange Rates: A Virtual Quest for Fundamentals, NBER Working Paper 4503.

Flood, Robert P., and Mark P. Taylor, 1995, Exchange Rate Economics: What's Wrong With the Conventional Macro Approach? Frankel, Galli and Giovannini, eds., the Microstructure of Foreign Exchange Markets (University of Chicago Press, Chicago).

Frankel, Jeffrey, and Kenneth Froot, 1990, Chartists, Fundamentalists and the Demand for Dollars, in A.S. Courakis and M.P. Taylor (eds.), Private Behavior and Government Policy in Interdependent Economies (Claredon Press), 73-126.

French, Kenneth R., and Richard Roll, 1996, Stock Return Variances: The Arrival of Information and the Reaction of Traders, Journal of Financial Economics 17. 5-26.

Friedman, Milton, 1953, Essays in Positive Economics (University of Chicago Press: Chicago).

Gallant, A. Ronald, Peter Rossi, and George Tauchen, 1992. Stock Prices and Volume, Review of Financial Studies 5, 199-242.

Goodhart, Charles, 1988, The Foreign Exchange Market: A Random Walk with a Dragging Anchor, Economica 55, 437-460.

Hart, O., and D. Kreps, 1986, Price Destabilizing Speculation, Journal of Political Economy 94, 927-952. 
Hau, Harald, 1995, Optimal Entry and Endogenous Risk in the Foreign Exchange Market, Mimeo, Princeton University.

Ito, Takatoshi, Richard K. Lyons, and Michael T. Melvin, 1966, Is There Private Information in the FX Market? The Tokyo Experiment, Mimeo, U.C. Berkeley.

Kouri, P.J.K., 1981, Balance of Payments and the Foreign Exchange Markets: A Dynamic Partial Equilibrium Model, NBER Working Paper 644.

Lyons, Richard K., 1995, Tests of Microstructural Hypotheses in the Foreign Exchange Market, Journal of Financial Economics 39, 321-51.

Osler, C., 1995, Exchange Rate Dynamics and Speculator Horizons, Journal of International Money and Finance 14, 695-719.

Osler, C., 1997, Short-Term Speculators and the Puzzling Behavior of Exchange Rates, forthcoming, Journal of International Economics.

Stein, J.L., 1961, Destabilizing Speculative Activity Can be Profitable, Review of Economics and Statistics 43, 301-302.

Stein, Jeremy C., 1987, Informational Externalities and Welfare-Reducing Speculation, Journal of Political Economy 95, 1123-45.

Tobin, James, 1974, The New Economics, One Decade Older (Princeton University Press, Princeton). 


\section{Notes}

1. We have called these actors current-account traders but some capital account transactions might belong here. Anyone whose currency demand is influenced by relative prices should be incorporated into this net demand. For example, decisions about direct investment may be influenced by the level of the real exchange rate.

2. This stylized interpretation of the exchange rate does not include any permanent shocks, which may strike some observers as contrary to facts. Including permanent shocks would not substantially affect our central conclusions. The exchange rate without speculators would be determined as follows: $e_{t}=e+\varepsilon_{t}+\omega_{t}$, where $\omega_{t}$ follows a random walk. The behavior of speculators (to be described later) would be only trivially affected by the inclusion of $\omega_{i}$ (their average absolute bet would decline). What matters for speculators is the expected exchange rate change and the exchange rate's variability conditional on available information. A nonzero value of $\omega_{t}$ can be interpreted, in this context, as a change in the underlying equilibrium (a change in $e$ ), which speculators will take into account in choosing their positions.

3. Here again, the distinction between current account and capital account agents is not as clearcur as suggested by the text. It is certainly possible that expected future exchange rate movements may influence some of the currency purchases of goods and services traders. A more general interpretation of the model incorporates this possibility. Specifically, we can interpret $S$ as a measure of the sensitivity of currency demand to relative prices, from whatever the source of such sensitivity; likewise, we can interpret $\mathrm{Nq}$ as a measure of the sensitivity of currency demand to expected excess returns, from whatever the source of such sensitivity.

4. This point is stressed in Lyons [1995], in discussing how traders use information on customers' market-orders. Another example: with a large stop-loss order a trader begins execution before the price actually reaches the exchange rate level specified by the order itself. The trader is counting on pressure from the order to push the exchange rate through and beyond the specified rate; in this way the trader can bring the average execution rate close to the specified rate.

5. This assumption implicitly sets interest rates as exogenous. Though reasonable for central bank intervention rates, the assumption may seem unrealistic for other rates that may matter for speculation. The results of the model are unchanged, however, if we allow interest rates to be determined partially endogenously. All that is required is that there be some shock affecting interest rates that is exogenous to the rest of the model.

6. In our model, the long-run behavior of the exchange rate depends on what happens to $C+S \varepsilon_{t}$ over time. None of our fundamental results require the stationarity of $C+S \varepsilon$. We assume stationarity to simplify our exposition.

7. The susbsequent analysis draws heavily on Osler (1997).

8. Speculators' long-run desired foreign currency holdings equals $q \Delta_{t}$ because, once the exchange rate reaches its long-run value and is no longer expected to change, $\Delta_{t}$ is the expected excess return on foreign currencies, while $q$ is their desired holdings per unit of excess return.

9. In the limit, when speculative activity as measured by $Q$ becomes arbitrarily large and $\lambda$ converges to unity, there is no risk premium at all and the exchange rate satisfies uncovered interest parity. 


\section{Appendix}

\section{A.I. Derivation of the solution for the model}

The solution begins with equation (11) from the text, which we repeat here for convenience as (A.1):

$$
E_{t} e_{t+1}-\left(1+S / Q_{t}\right) e_{t}-\frac{Q_{t-1}}{Q_{t}}\left[E_{t-1} e_{t}-e_{t-1}\right]=-\left[C+S \epsilon_{t}+Q_{t} \delta_{t}-Q_{t-1} \delta_{t-1}\right] / Q_{t}
$$

Taking $Q_{t-1}=Q_{t}=Q$ and setting $X_{t}=\left[C+S \varepsilon_{t}+Q\left(\delta_{t}-\delta_{l}\right)\right] / Q$ we get:

$$
E_{t} e_{t+1}-(1+S / Q) e_{t}-E_{t-1} e_{t}+e_{t-1}=-X_{t}
$$

In their appendix to Chapter 5, Blanchard and Fisher (1989) show how to solve this sort of equation both by the method of undetermined coefficients and by the factorization method. We follow the factorization method here.

Take expectations of (A.2) as of time $t-1$, denote by $F$ the forward operator which increases the date on $e$ but not the date on the expectations operator $E$, and denote by $L=F^{-1}$ the lag operator that decreases the date on $e$ but does not change the date of the expectations operator. Then collect terms:

$$
\left[F^{2}-(2+S / Q) F+1\right] L E_{t-1} e_{t}=-E_{t-1} X_{t}
$$

By factorization:

$$
(F-\lambda)\left(F-\frac{1}{\lambda}\right) L E_{t-1} e_{t}=-E_{t-1} X_{t}
$$

where $\lambda$ is the smaller root of the characteristic equation: $\lambda^{2}-(2+S / Q) \lambda+1=0$. 
Multiply (A.4) through by $-\lambda /(1-\lambda F)$ and expand to get:

$$
E_{t-1} e_{t}=\lambda e_{t-1}+\lambda \sum_{j=0}^{\infty} E_{t-1} X_{t+j}+C \lambda^{-t},
$$

where $C$ is an arbitrary constant. With the assumption that there are no explosive bubbles, $C=0$. Use (A.5) to substitute in (A.2) for $E_{t-1} e_{t}$ and, with a suitable change in the time index, for $E_{t} e_{t+1}$. After collecting terms and imposing $C=0$, one gets:

$$
(1-\lambda+S / Q) e_{t}=(1-\lambda) e_{t-1}+X_{t}+\sum_{j=0}^{\infty} \lambda^{j+1} E X_{t+1+j}-\lambda \sum_{j=0}^{\infty} \lambda^{j} E_{t-1} X_{t+j}
$$

From the factorization, the sum of the roots can be written $\lambda+1 / \lambda=2+S / Q$, and so:

$$
1-\lambda+\frac{S}{Q}=\frac{1}{\lambda}-1=\frac{1-\lambda}{\lambda} .
$$

Also,

$$
\frac{S}{Q}=\frac{1}{\lambda}-2+\lambda=\frac{(1-\lambda)^{2}}{\lambda}
$$

This means that

$$
\frac{\lambda}{1-\lambda}=(1-\lambda) \frac{Q}{S}
$$

From (A.7) and (A.8),

$$
\frac{1}{(1-\lambda+S / Q)}=(1-\lambda) \frac{Q}{S}
$$


Multiply both sides of (A.6) by (A.10), and note that $(1-\lambda)^{2} Q / S=\lambda$, to get

$$
e_{t}=\lambda e_{t-1}+(1-\lambda) \frac{Q}{S} \sum_{j=0}^{\infty} \lambda^{j}\left[E X_{t+j}-\lambda E_{t-1} X_{t+j}\right]
$$

Replace $X_{t}$ by $\left(C+S \varepsilon_{t}+Q \Delta_{t}\right) Q$, where $\Delta_{t} \equiv \delta_{t}-\delta_{t-1}$, let $\bar{e}=C / S$, and again note that $Q / S=\lambda(1-\lambda)^{2}$ for the result:

$$
\begin{aligned}
e_{t}=\lambda e_{t-1}+ & (1-\lambda) \bar{e}+(1-\lambda)\left(\varepsilon_{t}-\lambda E_{t-1} \varepsilon_{t}\right)+\frac{\lambda}{1-\lambda}\left(\Delta_{t}-\lambda E_{t-1} \Delta_{t}\right) \\
& +(1-\lambda) \sum_{j=1}^{\infty} \lambda^{j}\left(E_{t} \varepsilon_{t+j}-\lambda E_{t-1} \varepsilon_{t+j}\right)+\frac{\lambda}{1-\lambda} \sum_{j=1}^{\infty} \lambda^{j}\left(E_{t} \Delta_{t+j}-\lambda E_{t-1} \Delta_{t+j}\right)
\end{aligned}
$$

\section{A.II. Independently and Identically Distributed Shocks With Zero Means}

On the assumption that $E_{t-1} \varepsilon_{t+j}=E_{i} \varepsilon_{t+j}=E_{t-1} \Delta_{t+j}=E_{t} \Delta_{t+j}=0$, (A.12) reduces to:

$$
e_{t}=\lambda e_{t-1}+(1-\lambda) \bar{e}+(1-\lambda) \varepsilon_{t}+\frac{\lambda}{1-\lambda} \Delta_{t}
$$

This is shown in the text for period $t+1$ as equation (12).

For the moving average representation, multiply (A.13) through by $(1-\lambda L)^{-1}$ to obtain

$$
e_{t}=\bar{e}+(1-\lambda) \sum_{j=0}^{\infty} \lambda^{j} \varepsilon_{t-j}+\frac{\lambda}{1-\lambda} \sum_{j=0}^{\infty} \lambda^{j} \Delta_{t-j}
$$


If the $\varepsilon$ and $\Delta$ shocks are independently and identically distributed, then the unconditional variance of $e$ is:

$$
E\left[e_{t}-\bar{e}\right]^{2}=\frac{(1-\lambda)^{2}}{1-\lambda^{2}} \operatorname{Var}(\varepsilon)+\frac{\lambda^{2}}{(1-\lambda)^{2}} \frac{1}{1-\lambda^{2}} \operatorname{Var}(\Delta)
$$

To obtain the unconditional variance of the change in the exchange rate, use (A.14) and again assume independently and identically distributed shocks with zero means. The result is:

$$
E\left[e_{t}-e_{t-1}\right]^{2}=\frac{2}{1+\lambda} E\left[e_{t}-\bar{e}\right]^{2}
$$

With very little speculation and $\lambda$ close to zero, the variance of the change in the exchange rate is twice the variance of the level. With a lot of speculation and $\lambda$ close to one, the variance of the change in the exchange rate is about the same as the variance in the level.

\section{Uniqueness of Constant Solution}

Our solution for the conditional variance of the exchange rate assumes that $Q_{t}$ is a constant $Q$. However, since so many relationships are nonlinear, the uniqueness of the solution cannot be assumed. From $Q=N q$ and from the definition of $q$ in equation (7),

$$
Q=N /\left[\theta \operatorname{Var}\left(e_{t+1}\right)\right]
$$

From equation (22) for the exchange rate's conditional variance, combined with (A.9), we get:

$$
\operatorname{Var}\left(e_{t+1}\right)=(1-\lambda)^{2} \operatorname{Var}\left(\varepsilon_{t+1}\right)+\frac{\lambda^{2}}{(1-\lambda)^{2}} \operatorname{Var}\left(\Delta_{t+1}\right)
$$


Equations (A.9), (A.17), and (A.18) are three equations in $Q, \lambda$ and $\operatorname{Var}\left(e_{t+1}\right)$

given $\operatorname{Var}\left(\varepsilon_{t+1}\right), \operatorname{Var}\left(\Delta_{t+1}\right), S, \theta$, and $N$ as exogenous parameters. Eliminating $Q$ and $\operatorname{Var}\left(e_{t+1}\right)$ we have:

$$
\frac{N}{\theta S}=\lambda \operatorname{Var}\left(\varepsilon_{t+1}\right)+\frac{\lambda^{3}}{(1-\lambda)^{4}} \operatorname{Var}\left(\Delta_{t+1}\right)
$$

The right side of (A.19) becomes arbitrarily small as $\lambda$ approachees zero, and becomes arbitrarily large as $\lambda$ approaches unity. It is also monotonically increasing in $\lambda$. Therefore, for any value of the left side of (A.19), there is only one solution for $\lambda$. By (A.9), there is then only one solution for $Q$ and by (A.18) there is only one solution for $\operatorname{Var}\left(e_{t+1}\right)$. Furthermore, one can readily see from (A.9) and (A.19) that $\lambda$ and $Q$ are unambiguously higher when $N$ is higher.

\section{A.III. Autocorrelated Current-Account Shocks}

If $\varepsilon_{t}=\rho \varepsilon_{t-1}+\omega_{t}$, then (A.12) can be used to get an explicit solution. Note first that

$$
E_{r} \varepsilon_{t+j}=\rho^{\prime} \varepsilon_{i} \text { and } E_{t-1} \varepsilon_{t+j}=\rho^{j+1} \varepsilon_{t-1} .
$$

With these substitutions, the terms in (A.12) involving $\varepsilon$ shocks can be written

$$
\sum_{j=0}^{\infty} \lambda^{j}\left(\rho^{j} \varepsilon_{t}-\lambda \rho^{j+1} \varepsilon_{t-1}\right)=\frac{1}{1-\lambda \rho}\left(\varepsilon_{t}-\lambda \rho \varepsilon_{t-1}\right)=\frac{(1-\lambda) \rho \varepsilon_{t-1}+\omega_{t}}{1-\lambda \rho}
$$

This was used to obtain equation (25) in the text. 


\section{A.IV. Mean-Reverting Interest-Rate Differentials}

If $\delta_{t}=\alpha \delta_{t-1}+\eta_{t}$, we need to replace $\Delta_{t+j}$ by $\delta_{t+j}-\delta_{t+j-1}$ in (A.12). Then note that

$$
\begin{aligned}
& \delta_{t}-\delta_{t-1}=(\alpha-1) \delta_{t-1}+\eta_{t}, \\
& E_{t-1}\left(\delta_{t}-\delta_{t-1}\right)=(\alpha-1) \delta_{t-1}, \\
& E_{t}\left(\delta_{t+j}-\delta_{t+j-1}\right)=(\alpha-1) \alpha^{j-1} \delta_{t}=(\alpha-1)\left(\alpha^{j} \delta_{t-1}+\alpha^{j-1} \eta_{t}\right), \\
& E_{t-1}\left(\delta_{t+j}-\delta_{t+j-1}\right)=(\alpha-1) \alpha^{j} \delta_{t-1} .
\end{aligned}
$$

With these substitutions in (A.12), the summations for interest-rate changes reduce to

$$
-\frac{(1-\lambda)(1-\alpha)}{1-\alpha \lambda} \delta_{t-1}+\frac{1-\lambda}{1-\alpha \lambda} \eta_{t}
$$

This was used to generate equation (27) in the text. 
No. 93-101 Gordon M. Phillips, Robert J. Weiner

"Information and Normal Backwardation as Determinants of Trading Performance: Evidence from the North-Sea Oil Forward Market." 1994. The Economic Journal.

No. 93-102 Stephen R. Goldberg, Frank L. Heflin

"The Association Between the Level of International Diversification and Risk."

No. 93-103 John A. Carlson

"Risk Aversion, Foreign Exchange Speculation and Gambler's Ruin."

No. 93-104 John A. Carlson, Aasim M. Husain, Jeffrey A. Zimmerman

"Penalties and Exclusion in the Rescheduling and Forgiveness of International Loans."

No. 93-105 Kent D. Miller

"Industry and Country Effects on Manager's Perceptions of Environmental Uncertainties."

1993. Journal of International Business Studies, 24: 693-714.

No. 93-106 Stephen R. Goldberg and Joseph H. Godwin

"Foreign Currency Translation Under Two Cases-Integrated and Isolated Economies."

No. 93-107 Kent D. Miller

"A Comparison of Managers' Uncertainty Perceptions and Country Risk Indices."

No. 93-108 Jon D. Haveman

"The Effect of Trade Induced Displacement on Unemployment and Wages."

No. 93-109 Jon D. Haveman

"Some Welfare Effects of Dynamic Customs Union Formation."

No. 93-110 John A. Carlson, Insook Kim

"Central Banks' Expected Profits From Intervention."

No. 94-001 Casper G. De Vries, Phillip A. Stork, Kees G. Koedijk

"Between Realignments and Intervention: The Belgian Franc in the European Monetary System."

No. 94-002 Casper G. de Vries, K. U. Leuven

"Stylized Facts of Nominal Exchange Rate Returns."

No. 94-003 Kent D. Miller

"Operational Flexibility Responses to Environmental Uncertainties."

No. 94-004 Kent D. Miller

"Economic Exposure and Integrated Risk Management."

No. 94-005 Kent D. Miller

"Diversification Responses to Environmental Uncertainties."

No. 94-006 John M. Hannon, Ing-Chung Huang, Bih-Shiaw Jaw

"International Human Resource Strategy and Its Determinants: The Case of Multinationals and Their Subsidiaries in Taiwan."

No. 94-007 John M. Hannon, Ing-Chung Huang, Bih-Shiaw Jaw

"International Human Resource Strategy and Control: The Case of Multinationals and Their

Subsidiaries." 
No. 94-008 John M. Hannon, Yoko Sano

"Customer-Driven Human Resource Policies and Practices in Japan."

No. 94-009 John A. Carlson, Insook Kim

"Leaning Against the Wind: Do Central Banks Necessarily Lose?"

No. 94-010 John A. Carlson, David W. Schodt

"Beyond the Lecture: Case Teaching and the Learning of Economic Theory."

No. 94-011 Alok R. Chaturvedi, Hemant K. Jain, Derek L. Nazareth

"Key Information Systems Management Issues in Developing Countries: Differences in the Indian and US Contexts."

No. 94-012 Jon Haveman,

"The Influence of Changing Trade Patterns on Displacements of Labor."

No. 94-013 Stephen Goldberg, Charles A. Tritschler, Joseph H. Godwin

"Financial Reporting for Foreign Exchange Derivatives."

No. 94-014 Charles Noussair, Charles Plott, Raymond Riezman

"Una investigacion experimental sobre la estructura del comercia interncional (Spanish Version)."

Translated: "An Experimental Investigation About the Structure of International Commerce."

No. 94-015 Marie Thursby, Richard Jensen

"Patent Races, Product Standards, and International Competition."

No. 94-016 Kent D. Miller, Jeffrey J. Reuer

"Firm Strategy and Economic Exposure to Foreign Exchange Rate Movements."

No. 94-017 John Hannon, Yoko Sano

"The Determinants of Corporate Attractiveness in Japan."

No. 94-018 John Hannon, Ing-Chung Huang, Cheng-Chen Lin

"The Mediating Effect of Pre/Post Assignment Acitivities on the Quality of Work Life of Expatriates:

Evidence for Managers in the P.R.C."

No. 94-019 John Hannon, Ing-Chung Huang, Cheng-Chen Lin

"The Mediating Effects of Organization Commitment and Job Involvement on the Relationship Between Quality of Work Life and Customer Service Attitudes."

No. 94-020 John A. Carlson, Marc Surchat

"A Model for Filter-Rule Gains in Foreign Exchange Markets."

No. 94-021 Ch.N. Noussair, Ch.R. Plott, R. Riezman

"The Principles of Exchange Rate Determination in an International Finance Experiment."

No. 94-022 Stephen R. Goldberg, Joseph H. Godwin, Myung-Sun Kim, Charles A. Tritschler "On The Determinants of Corporate Hedging With Financial Derivatives."

No. 95-001 Timothy B. Folta

"Sovereignty Conditions and Governance Modes: An Option Theory Approach."

No. 95-002 John A. Carlson, Dong-Geun Han

"Monetary Coordination, Fixed Exchange Rates and Noisy Markets."

No. 95-003 Jon D. Haveman

"Can Barriers to Trade Make a Differential?" 
No. 95-004 Kent D. Miller and Jeffrey J. Reuer

"Asymmetric Corporate Exposures to Foreign Exchange Rates."

No. 95-005 Gerald J. Lynch and Bradley T. Ewing

"Money Growth Variability and the Term Structure of Interest Rates in Japan."

No. 95-006 Nicholas C. Petruzzi and Maqbool Dada

"Inventory and Pricing in Global Operations: Learning from Observed Demand."

No. 95-007 Kala Krishna and Marie Thursby

"Whither Flat Panel Displays?"

No. 96-001 Thomas Brush, Catherine Maritan, Aneel Karnani

"Managing a Network of Plants Within Multinational Firms."

No. 96-002 John J. McConnell, Heidi J. Dybevik, David Haushalter, Erik Lie

"A Survey on Domestic and International Stock Exchange Listings with Implications for Markets and Managers."

No. 96-003 Kala Krishna, Suddhasatwa Roy, Marie Thursby

"Implementing Market Access"

No. 96-004 Jon Haveman, David Hammels

"Trade Creation and Trade Diversion: New Empirical Results"

No. 96-005 Riki Takeuchi, John M. Hannon

"Antecedents of Expatriate Spouse Adjustments: An Analysis of Japanese Spouses in the United States"

No. 96-006 Bih-Shiaw Jaw, John M. Hannon

"Determinants of International and Intercultural Human Resource Control: The Case Of Taiwanese Subsidiaries in the People's Republic of China"

No. 96-007 John M. Hannon, Riki Takeuchi

"Adjustment and Job Satisfaction as Antecedents of Intent to Stay: The Case of Japanese Expatriates in the United States"

No. 96-008 John M. Hannon

"Using International Human Resource Management to Inform the Business Intelligence Function"

No. 96-009 Jeffrey J. Reuer, Kent D. Miller

"Agency Costs and the Performance Implications of International Joint Venture Internalization"

No. 96-010 Neven Valev

"International Lending by U.S. Banks"

No. 96-011 Kala Krishna, Marie Thursby, Suddhasatwa Roy

"Implementing Market Access" (revised)

No. 96-012 Jon D. Haveman

"The Effect of Trade Induced Displacement on Unemployment and Wages"

No. 96-013 Robert A. Buckle and John A. Carlson

"Inflation and Asymmetric Price Adjustment"

No. 97-001 Jeffrey J. Reuer

"Shareholder Wealth Effects of Joint Venture Termination: A Transaction Cost Analysis"

No. 97-002 Jon Haveman and David Hummels

"Multinationals, Intrafirm Trade and Intraindustry Trade" 
No. 97-003 Douglas Bowman, John U. Farley, and David C. Schmittlein "Cross-National Empirical Generalization of a Supplier Section and Usage Model for Foreign Exchange Services"

No. 97-004 Kent D. Miller

"Measurement of Perceived Environmental Uncertainties: Response and Extension

No. 97-005 John A. Carlson and C. L. Osler

"Rational Speculators and Exchange Rate Volatility" 